\title{
Household Air Pollutionin Rural Western Kenya: A Major Public Health Challenge
}

\author{
*Carol Munini Munyao ${ }^{1}$, Gelas Muse Simiyu², Kipkorir K. G. Kiptoo², \\ John K. Chelal ${ }^{3}$

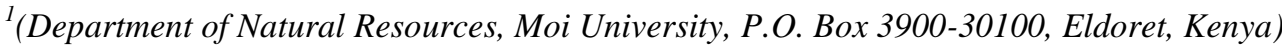 \\ ${ }^{2}$ (Department of Environmental Biology and Health, University of Eldoret, P.O. Box 1125-30100, Kenya) \\ ${ }^{3}$ (Department of Agriculture \&Biotechnology, Moi University, P.O Box 3900-30100, Eldoret, Kenya) \\ Corresponding Author: Carol Munini Munyao
}

\begin{abstract}
The use of biomass fuels poses great threats to public health accounting for $32 \%$ of the total attributable burden of diseases due to Indoor Air Pollution (IAP) in Africa. Heavy reliance on biomass fuels for household energy in Kenya makes the country more vulnerable with $90 \%$ of the rural population relying on biomass fuels for domestic purposes. The objective of this study was to assess effectiveness of improved biomass cookstoves in reducing kitchen $P M_{2.5}$ concentration in Western Kenya region. The data was collected through continuous real-time monitoring of kitchen pollution concentration for a period of 24 hours using UCB-PATS, CO monitors, questionnaires and time activity budgets. Data analysis was undertaken by performing ANOVA to test for their variations from WHO stipulated safe standards. The study found that at 95\% CI, mean 24-hr kitchen $\mathrm{CO}$ and PM concentrations from all the stoves were significantly higher than the stipulated WHO threshold. Three-stone fire had the highest average 24-hour kitchen PM and CO emissions using firewood at $4272.414 \mu \mathrm{g} / \mathrm{m}^{3}(p=0.000)$ and $75.4417 \mathrm{ppm}(p=0.000)$, respectively, while Chepkube stove had the least at $682.646 \mu \mathrm{g} / \mathrm{m}^{3}(p=0.000)$ and $8.7224 \mathrm{ppm}(p=0.000)$, respectively. It was concluded that, improved biomass stoves provided an overall reduction in pollutant concentration compared to three-stone fire but the local innovation Chepkube stove that has been classified as ungraded stove had the highest pollutant reduction. In addition, indoor air pollution in rural areas is a real health risk. Consequently, it was recommended that programs aiming to reduce the adverse health impacts of $\mathrm{CO}$ and PM${ }_{2.5}$ should focus on measures that result in larger reductions of $P M_{2.5}$ emissions especially during burning and peak periods.
\end{abstract}

Keywords: Indoor air pollution, Household air pollution, Particulate matter, Carbon monoxide, Public health, Chepkube, Cheprocket

\section{Introduction}

Household Air Pollution (HAP) from biomass cooking fuels has been linked to several respiratory diseases such as acute lower respiratory infections and chronic obstructive pulmonary disease and is therefore is a major cause of morbidity and mortality globally especially in developing economies (WHO 2007). A large part of this is due to developing countries' reliance on traditional, unprocessed biomass fuels such as wood, crop residues, and waste. Approximately half the world's population and up to $90 \%$ of rural households in developing countries still rely on unprocessed biomass fuels in the form of wood, dung and crop residues (UNEP, 1998). In Kenya, over 90\% of rural population rely on solid biomass fuels (GoK, 2002). According to the 2009 Population and Housing census, the main sources of cooking energy is firewood at $93.4 \%$ and $71 \%$ in Bungoma and Trans Nzoia Counties respectively. These fuels typically burnt indoors in open fires or poorly functioning stoves. Under these conditions, the fuels do not burn completely and result into complex mixture of products of incomplete combustion (PICs). Some of PICs include pollutants such as particulate matter (PM), carbon monoxide $(\mathrm{CO})$, nitrogen dioxide $\left(\mathrm{NO}_{2}\right)$, sulphur dioxide $\left(\mathrm{SO}_{2}\right)$, formaldehyde and polycyclic aromatic hydrocarbons (PAH), including benzo $[a]$ pyrene (Ezzati\&Kammen 2002), a carcinogen. According to Naeheret al. (2007), it is still not clear which other pollutants are contained in biomass smoke as there could be hundreds of other health damaging chemical pollutants. In addition to direct effects on IAP and health, carbon dioxide and black carbon emissions from burning solid fuels are also important contributors to global climate change (Ramanathan\& Carmichael 2008). Indoor air pollution (IAP) in developing countries contributes to up to $76 \%$ of the global particulate matter (PM); an important air pollutant and CO exposure. As a result there are high levels of air pollution, to which women, especially those responsible for cooking, and their young children, are most heavily exposed (Bruce et al., 2008). Household Air Pollution (HAP) in rural Kenya is a major cause of morbidity and mortality due to overreliance of solid biomass fuels for domestic cooking. High poverty levels in 
these areas do not allow the communities to move up energy ladder to cleaner fuels or adopt improved energy technologies therefore larger population remains exposed. Worse still, cooking is a daily activity implying that household air pollution is a lifetime challenge to women who are the main domestic cooks and young children always accompanying them during cooking remain exposed. In Kenya like majority of developing countries, there have been efforts to reduce indoor air pollution through introduction and promotion of improved cook stoves by mainly Non-governmental organizations. Mud rocket stove and Cheprocket stove are such stoves disseminated in the Elgon sub-county through VI-agro forestry program despite limited information on their performance in terms of kitchen PM and $\mathrm{CO}$ emissions reduction and therefore associated health risks unknown. Systematic evaluations to assess whether these programs have achieved the intended efforts of reducing indoor air pollution are lacking. Still, majority of improved biomass cookstoves are disseminated through energy saving programs whose main aim is to cut on fuelwood consumption and not necessarily reduction in IAP. Chepkube stove, the highest adopted stove in the North rift region is untested for PM and CO emissions levels. Absence of this information hinders proper planning by the county governments on public health issues. The main objective of this study was to assess indoor air pollution due to particulate matter and carbon monoxide emissions from biomass fuels use. The study concentrated on determination of kitchen concentrations of particulate matter and carbon monoxide from four biomass stoves in Kaptama Sub-location, Bungoma County and Kapsara Sub-location, Trans Nzoia County, Kenya.This study is essential because it would provide information on the effectiveness of improved biomass stoves in reducing fuel use and kitchen concentrations of PM and CO using different biomass fuels. Finding from this study could assist planners and policy makers on mitigation of household air pollution in Kenya. Planning opportunities to be derived from this study include formulation of a domestic biomass utilization policy that would enhance energy accessibility, control health burden from household air pollution and minimize environmental stress from biomass smoke. Finally, enhancement of the household air quality would make a significant impact on the rural economies by reducing disease burden especially on women and children thus improving their health and minimizing costs spent on hospital bills.

\subsection{Study Site}

\section{Materials And Methods}

This study was undertaken in two Counties in the Western region of Kenya. They included the Trans Nzoia and Bungoma Counties.

\subsubsection{Position and Location of Trans Nzoia County}

Trans Nzoia County is one of the forty seven (47) counties in Kenya and it has three sub-counties. The County comprises five constituencies namely Endebess, Cherangany, Saboti, Kwanza and Kiminini. The county borders the Republic of Uganda to the West, Bungoma and Kakamega Counties to the South, West Pokot County to the East and ElgeyoMarakwet and UasinGishu Counties to the South East. The county approximately lies between latitudes $0^{\circ} 52^{\prime}$ and $10^{\circ} 18^{\prime}$ North of the equator and longitudes $34^{\circ} 38^{\prime}$ and $35^{\circ} 23^{\prime}$ East of the Great Meridian as indicated in Figure 1. The County covers an area of $2,495.6 \mathrm{~km}^{2}$ which forms $0.42 \%$ of the total land area of the Republic of Kenya (GoK, 2013a).

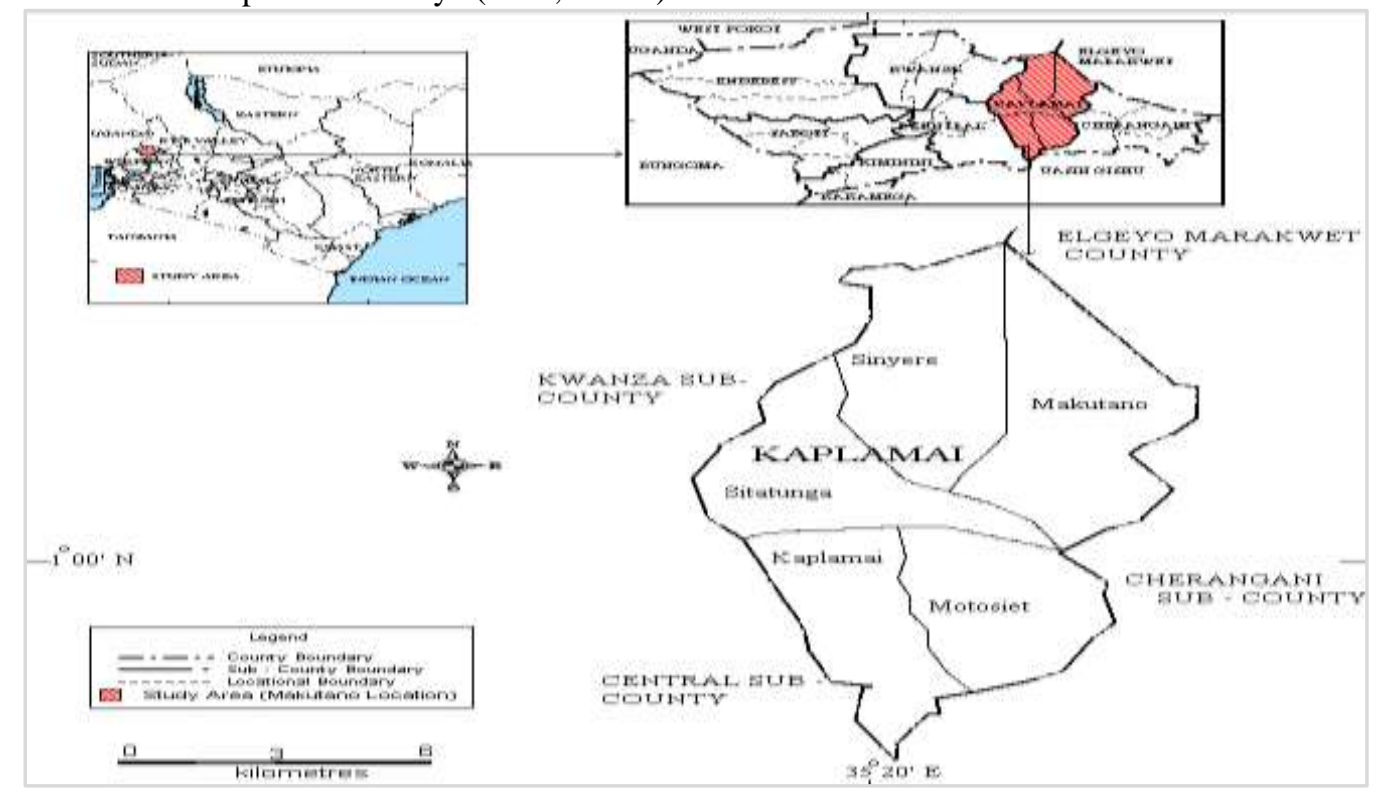

Figure 1: Trans Nzoia County indicating Location of Kaplamai Sub-county

Source: Moi University, 2017 


\subsubsection{Climatic Conditions of Trans Nzoia County}

The County has a highland equatorial type of climate. The rainfall is well distributed throughout the year. The annual rainfall ranges between $900 \mathrm{~mm}$ and $1400 \mathrm{~mm}$. The slopes of Mt. Elgon to the west receive the highest amount of rainfall while the region bordering West Pokot County receives the least. The County experiences bi-modal rainfall pattern. The long rains occur from April to June, while the short rains fall from July to October. The mean temperature in the County is $18.6{ }^{\circ} \mathrm{C}$. However, temperatures range from a low of 10 ${ }^{\circ} \mathrm{C}$ to a high of $30{ }^{\circ} \mathrm{C}$. The county has favourable climate for both livestock and crop production and vegetation growth (GoK, 2013a).

The study was undertaken in Lower Highland Zone that covers the slopes of Mt Elgon and Cherangany Hills with an altitude ranging from $1,800 \mathrm{~m}$ to $2,400 \mathrm{~m}$ above sea level. This zone covers $848.64 \mathrm{~km}^{2}$ and it constitutes $34 \%$ of the total area of the County (GoK, 2013a).The soils found in this zone are red and brown clays derived from volcanic ash. These soils are fertile with a high content of clay mineral which gives a continuous supply of plant nutrients (GoK, 2013a).

\subsubsection{Position and Location of Bungoma County}

Bungoma County lies between latitude $0^{\circ} 28^{\prime}$ and latitude $1^{\circ} 30^{\prime}$ North of the Equator, and longitude $34^{\circ} 20^{\prime}$ East and $35^{\circ} 30^{\prime}$ East of the Greenwich Meridian. The County covers an area of $3032.4 \mathrm{~km}^{2}$. It boarders the republic of Uganda to the North west, Trans Nzoia County to the North-East, Kakamega County to the East and South East, and Busia County to the West and South West as shown in Figure 2.

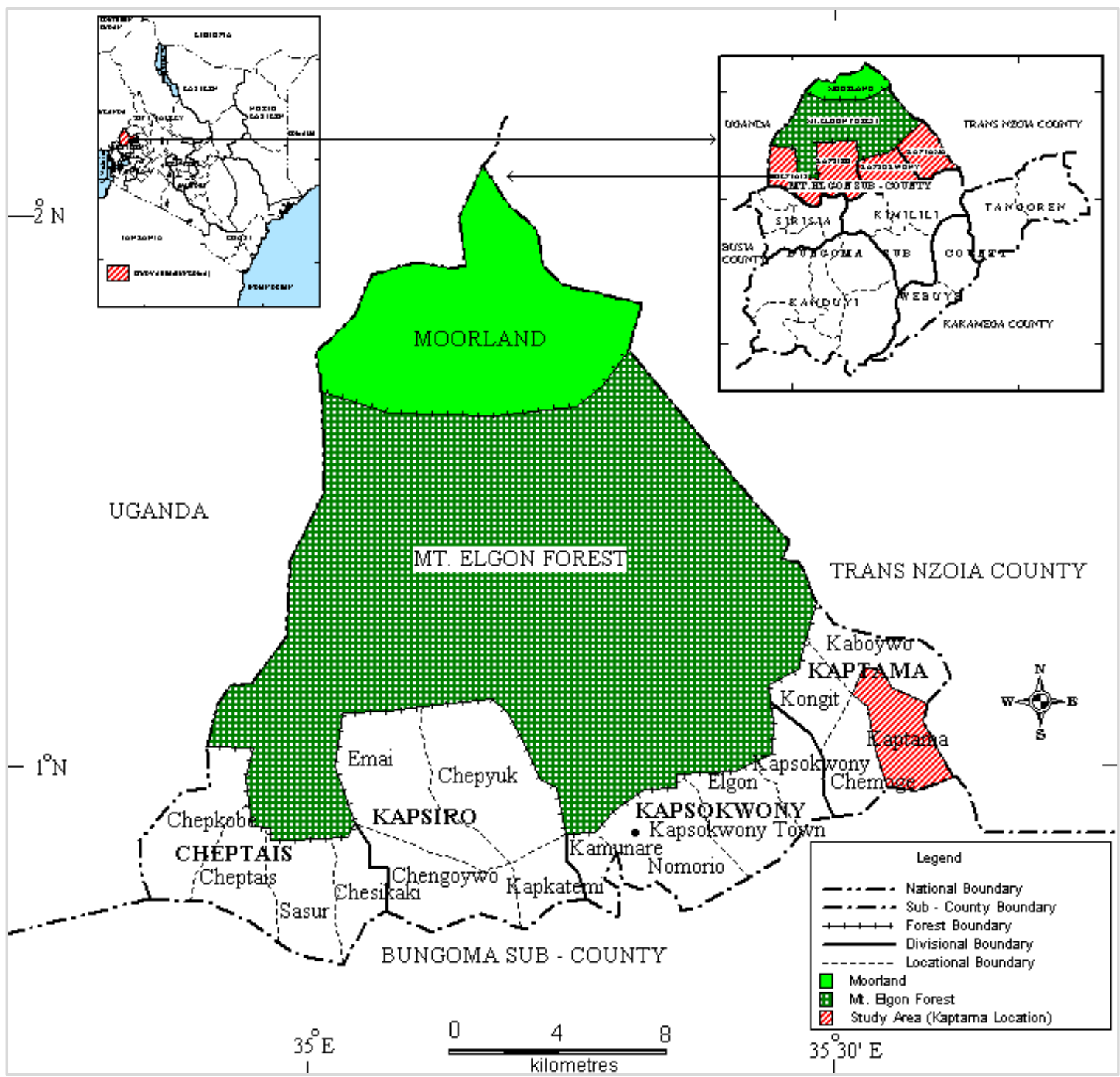

Figure 2: Location of Mt. Elgon Sub-county in Bungoma County

Source: Moi university, 2017 


\subsubsection{Climatic Conditions of Bungoma County}

The County experiences two rainy seasons; the long rains which run from March to July and short rains which run from August to October. The annual rainfall in the County ranges from $400 \mathrm{~mm}$ (lowest) to $1,800 \mathrm{~mm}$ (highest). The annual temperature in the County vary between $0{ }^{\circ} \mathrm{C}$ and $32{ }^{\circ} \mathrm{C}$ due to different levels of attitude, with the highest peak of Mt. Elgon recording slightly less than $0{ }^{\circ} \mathrm{C}(\mathrm{GoK}, 2013 \mathrm{~b})$. The altitude of the County ranges from over $4,321 \mathrm{~m}$ at the mountain side to $1200 \mathrm{~m}$ above sea level in the lower areas. The study was undertaken at the lower areas with altitude ranging between $1800 \mathrm{~m}$ to $2100 \mathrm{~m}$ above sea level. These regions are highly settled since they have fertile alluvial soils that are well drained for agricultural purposes. The high population pressure in the County has led to encroachment on protected forests for farming purposes and energy resources.

\subsection{Research Design}

This research employed cross-sectional study design where there was quantification of indoor air pollution and personal exposure levels of improved biomass stoves users and traditional biomass stove users and comparing these levels against WHO safe limits. Both quantitative and qualitative research methods were applied. Quantitative research method was used during measurement of concentrations of pollutants while qualitative research method entailed use of key informants and observations in order to get opinions regarding biomass stoves. A systematic approach to the study design entailed sampling, data collection through pre-testing of emission meters and revision of questionnaires, data coding and analysis.

\subsection{Sampling method}

A multi-stage sampling technique was used in this study where Trans Nzoia and Bungoma Counties were selected purposively because both have major ecosystems where efforts have been made to promote biomass stoves aimed at ecosystem conservation and indoor air pollution reduction. Kaplamai Sub-county in Trans Nzoia county and Elgon Sub- county in Bungoma count were selected purposively because in these subcounties, divisions where stove promotion was undertaken are found. Selection of respondents from each village was done using random systematic sampling method where a list of all households in each village was given; top households were then picked according to the number attained after apportioning each village as per the sample population. A total of 204 households were selected as the sample size for HH survey. Selection of households for indoor air monitoring was done through quasi system because of time constraints and financial constraints. The criterion used was; first, the household must be using either Chepkube stove, or Cheprocket stove or rocket stove or three stone stoves and the household size to be above 7 members which was the main HH size recorded in both Counties from survey data. Same household size was used to reduce disparities among recorded emissions. A total of $56 \mathrm{HH}$ were selected for indoor air pollution monitoring; 14 rocket stoves, 16 Chepkube stoves, 10 three stone and 16 Cheprocket.

\subsection{Data collection}

University of California Berkeley-Particle and Temperature Sensors (UCB-PATS) instruments were used to monitor the levels of $\mathrm{PM}_{2.5}$ in the kitchens. The UCB-PATS use smoke detector technology, which combines chambers of photoelectric sensors (of light dispersion) and ionization (loss of ions by particles in suspension). This combination guarantees precise measurements of fine particles. The light dispersion chamber uses a light emitting diode (LED), with a wavelength of $880 \mathrm{~nm}$, and a photodiode that measures the light intensity scattered in an angle of $45^{\circ}$. Even though the UCB does not select particles, using a device of traditional cut-off size as the cyclones, the photoelectric sensor is more sensitive to particles smaller than $2.5 \mu \mathrm{m}$ aerodynamic diameter (University of California, 2016). While for carbon monoxide, a CO monitor was used to determine the kitchen levels. Concentrations were measured for one 24-hr period for each of the 56 households. Real-time signals were measured every second and the average concentration logged every minute, which was subsequently downloaded onto a computer. The monitor measures mass concentrations between 1 to $400 \mathrm{mg} / \mathrm{m}^{3}$ for particles with aerodynamic diameters between 0.1 and $10 \mu \mathrm{m}$. The monitors have an accuracy of $\pm 5 \%$ of the reading (University of California, 2003). Both UCB-PATS instrument and CO loggers were launched in kitchens and placed away from the fire $1.5 \mathrm{~m}$ above the ground. Both monitors were launched for 24 hours. All the kitchen monitors were placed in a mesh wire basket hanged from the kitchen roof to a height standard of 1.5 $\mathrm{m}$ above the ground, which is the average breathing height of a standing woman and young children carried on her back (Moradi, 2006).

\subsection{Data Analysis}

Data was analyzed using Statistical Packages for the Social Sciences (SPSS). Kitchen and personal CO measures were computed in to short-term time scales including; 1 hour, 24 hour and long-term time scales. Units of analysis included means, standard deviations, minimum values, median values and maximum values and IQR. One-way ANOVA was used to compare the variation of quantified kitchen and personal PM and CO 
concentrations from different stoves to WHO thresholds and further multiple tests of mean separation were done according to Tukey's test of significance at $p<0.05$. Graphs, tables and means were used to present results.

\section{Results}

Kitchen concentrations of particulate matter and carbon monoxide using both improved and traditional biomass stoves for wood and crop residue biomass fuels were provided.

\subsection{Kitchen $\mathbf{P M}_{2.5}$ Concentrations}

At 95\% CI, average 24-hour kitchen $\mathrm{PM}_{2.5}$ concentrations from all the stoves were significantly $(p=$ 0.000) higher than stipulated WHO threshold. Three stone stove had the highest average 24-hour PM emissions at $7022.245 \mu \mathrm{g} / \mathrm{m}^{3}(p=0.000)$ using crop residues as fuel and $4272.414 \mu \mathrm{g} / \mathrm{m}^{3}(p=0.000)$ using firewood as indicate in Figure 4.1. Particulate matter concentration was least from Chepkube stove using firewood at $682.646 \mu \mathrm{g} / \mathrm{m}^{3}(p=0.000)$ while Cheprocket produced the least $\mathrm{PM}_{2.5}$ emissions when crop residues were used as fuel at $2773.531 \mu \mathrm{g} / \mathrm{m}^{3}(p=0.000)$ as fuel as shown in Figure 3.
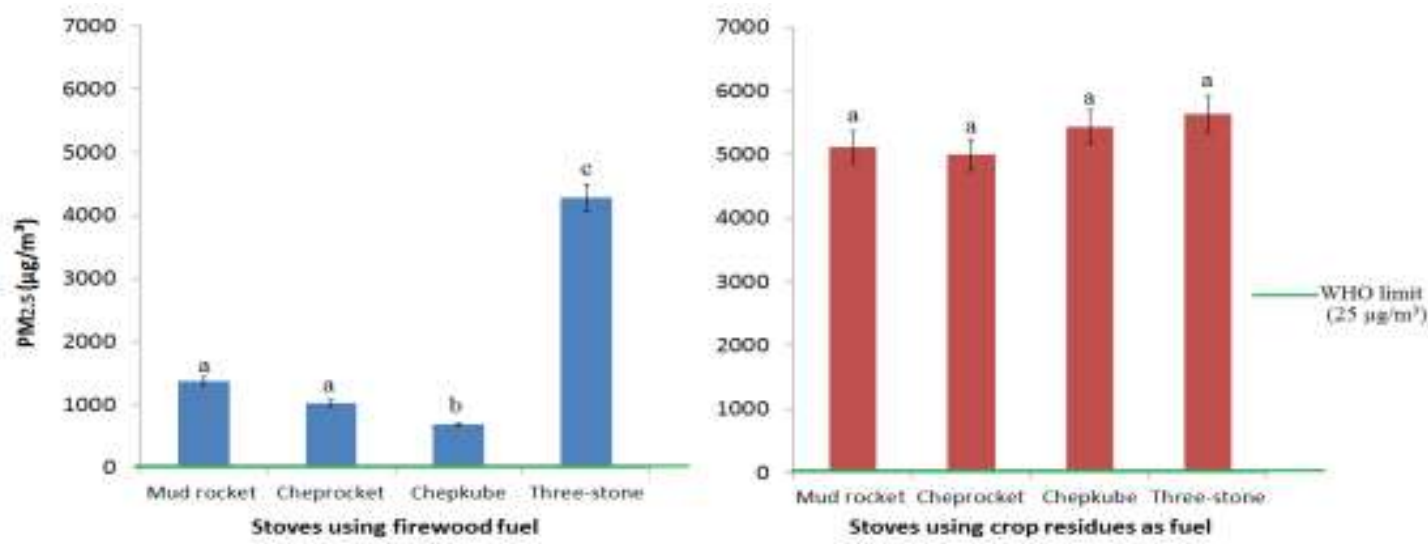

Figure 3: Mean 24-hr Kitchen $\mathrm{PM}_{2.5}$ Concentrations

NB: Bars designated with same letter within a fuel type are not statistically different at $p<0.05$ based on Tukey's test.

There were diurnal variations in the manner in which PM emissions were emitted from various biomass stoves and fuel type. Particulate matter emissions were high in kitchens using MRS using crop residues during simmering period at approximately $5000 \mu \mathrm{g} / \mathrm{m}^{3}(p=000)$ while maximum recorded kitchen concentration $\mathrm{PM}_{2.5}$ emissions was $28,211.4 \mu \mathrm{g} / \mathrm{m}^{3}\left(\mathrm{~min}-4663.6 \mu \mathrm{g} / \mathrm{m}^{3}, \mathrm{IQR}-149.814 \mu \mathrm{g} / \mathrm{m}^{3}, p=0.000\right)$ and $15153.5 \mu \mathrm{g} / \mathrm{m}^{3}(\mathrm{~min}$ $\left.-791.0 \mu \mathrm{g} / \mathrm{m}^{3}, \mathrm{IQR}-241.479 \mu \mathrm{g} / \mathrm{m}^{3}, p=0.000\right)$ using crop residues and firewood fuels respectively. Periodic variations also indicate that there were three major meals cooked in the households as indicated in Figure 4.
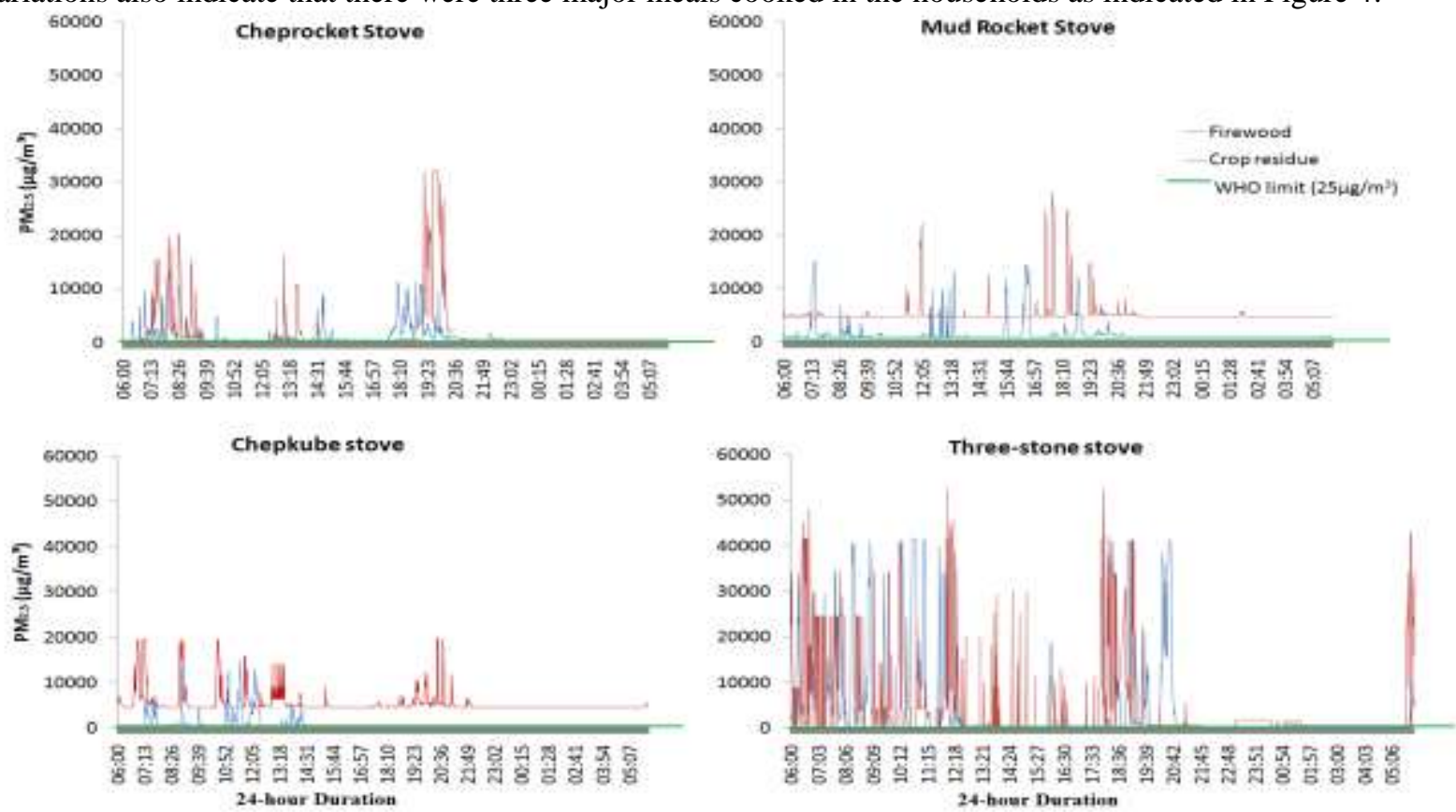

Figure 4: Diurnal Variation of $\mathrm{PM}_{2.5}$ using Different Biomass Stoves 
Diurnal variations in Figure 4 indicated that simmering period in the Chepkube stove using crop residues was higher compared to firewood. Maximum kitchen $\mathrm{PM}_{2.5}$ concentration recorded using Chepkube stove was $19,884.1 \mu \mathrm{g} / \mathrm{m}^{3}\left(\mathrm{~min}-4529.5 \mu \mathrm{g} / \mathrm{m}^{3}, \mathrm{IQR}-281.33 \mu \mathrm{g} / \mathrm{m}^{3}, p=0.000\right)$ and $15,214.0 \mu \mathrm{g} / \mathrm{m}^{3}(\mathrm{~min}-$ $\left.215.5 \mu \mathrm{g} / \mathrm{m}^{3}, \mathrm{IQR}-49.30 \mu \mathrm{g} / \mathrm{m}^{3}, p=0.000\right)$ using crop residues and firewood fuels respectively. Maximum kitchen $\mathrm{PM}_{2.5}$ concentration recorded using Cheprocket stove was $16,121.7 \mu \mathrm{g} / \mathrm{m}^{3}\left(\mathrm{~min}-210.4 \mu \mathrm{g} / \mathrm{m}^{3}, \mathrm{IQR}-\right.$ $\left.524.511 \mu \mathrm{g} / \mathrm{m}^{3}, p=0.000\right)$ and $32,149.9 \mu \mathrm{g} / \mathrm{m}^{3}\left(\mathrm{~min}-387.8 \mu \mathrm{g} / \mathrm{m}^{3}, \mathrm{IQR}-280.574 \mu \mathrm{g} / \mathrm{m}^{3}, p=0.000\right)$ using firewood and crop residues fuels respectively.

Kitchen $\mathrm{PM}_{2.5}$ concentrations using three-stone fire was continous during the day whether crop residues or firewood were used as fuel as indicated in Figure 4, which contributed to the high levles of $\mathrm{PM}_{2.5}$ recorded. The highest recorded kitchen $\mathrm{PM}_{2.5}$ concentration using crop residues was from three-stone fire at 52,639.7 $\mu \mathrm{g} / \mathrm{m}^{3}\left(\min -5.0 \mu \mathrm{g} / \mathrm{m}^{3}, \mathrm{IQR}-4062.221 \mu \mathrm{g} / \mathrm{m}^{3}, p=0.000\right)$ and $41,780.3 \mu \mathrm{g} / \mathrm{m}^{3}\left(\mathrm{~min}-19.7 \mu \mathrm{g} / \mathrm{m}^{3}, \mathrm{IQR}-\right.$ $\left.2531.871 \mu \mathrm{g} / \mathrm{m}^{3}, p=0.000\right)$.

\subsection{Kitchen Concentration of Carbon Monoxide}

At $95 \% \mathrm{CI}$, three-stone stove had the highest average kitchen $\mathrm{CO}$ concentrations at $75.4417 \mathrm{ppm}(p=$ 0.000) using crop residues as fuel while Chepkube stove had the least average 24-hour kitchen CO concentrations of $8.8171 \mathrm{ppm}(p=0.000)$ as indicate in Figure 5. Chepkube stove recorded the least kitchen CO concentrations using wood as fuel at $8.7224 \mathrm{ppm}(p=0.000)$ as indicated in Figure 5.
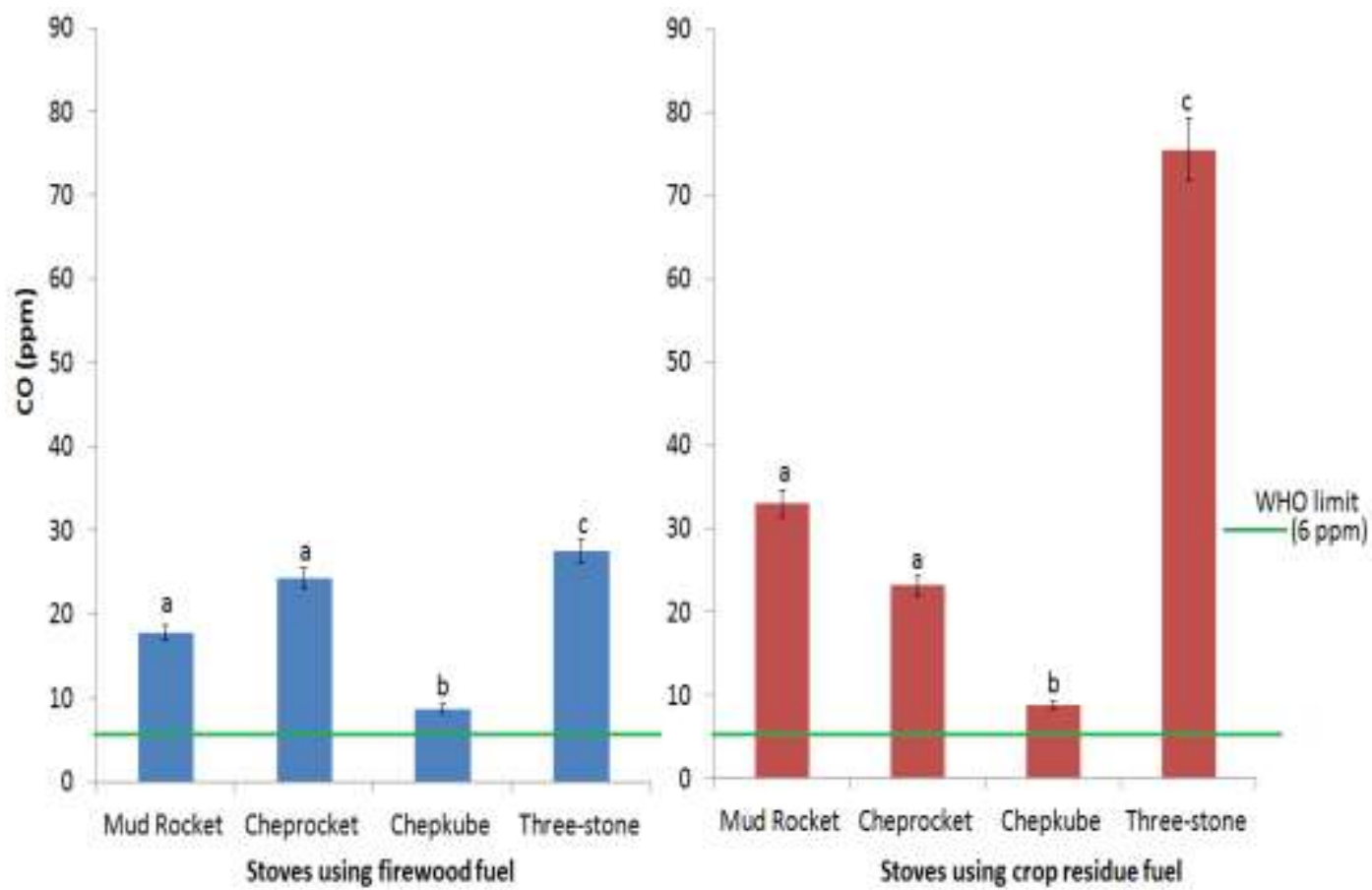

Figure 5: Average 24-hr Kitchen CO Concentrations using Different Biomass Stoves

NB: Bars designated with same letter within a fuel type are not statistically different at $p<0.05$ based on Tukey's test.

The highest recorded kitchen CO emission was from Cheprocket stove at $658 \mathrm{ppm}(\mathrm{min}-0.00 \mathrm{ppm}$, IQR $-3.50 \mathrm{ppm}, p=0.000)$ and $304 \mathrm{ppm}(\mathrm{min}-0 \mathrm{ppm}, \mathrm{IQR}-12.5 \mathrm{ppm}, p=0.000)$ using crop residues and firewood fuels, respectively. Kitchen CO concentrations recorded from MRS were $466.6 \mathrm{ppm}$ (min - $0 \mathrm{ppm}$, $\mathrm{IQR}-27 \mathrm{ppm}, p=0.000)$ and $163.5 \mathrm{ppm}(\mathrm{min}-0 \mathrm{ppm}, \mathrm{IQR}-19.25 \mathrm{ppm}, p=0.000)$ using crop residues and firewood fuels, respectively. There were several peak CO emissions from all the biomass stoves using both crop residues and firewood as fuel that exceeded both WHO safe guideline of $30 \mathrm{ppm}$ and warning level of $50 \mathrm{ppm}$ as indicated in Figure 6. 

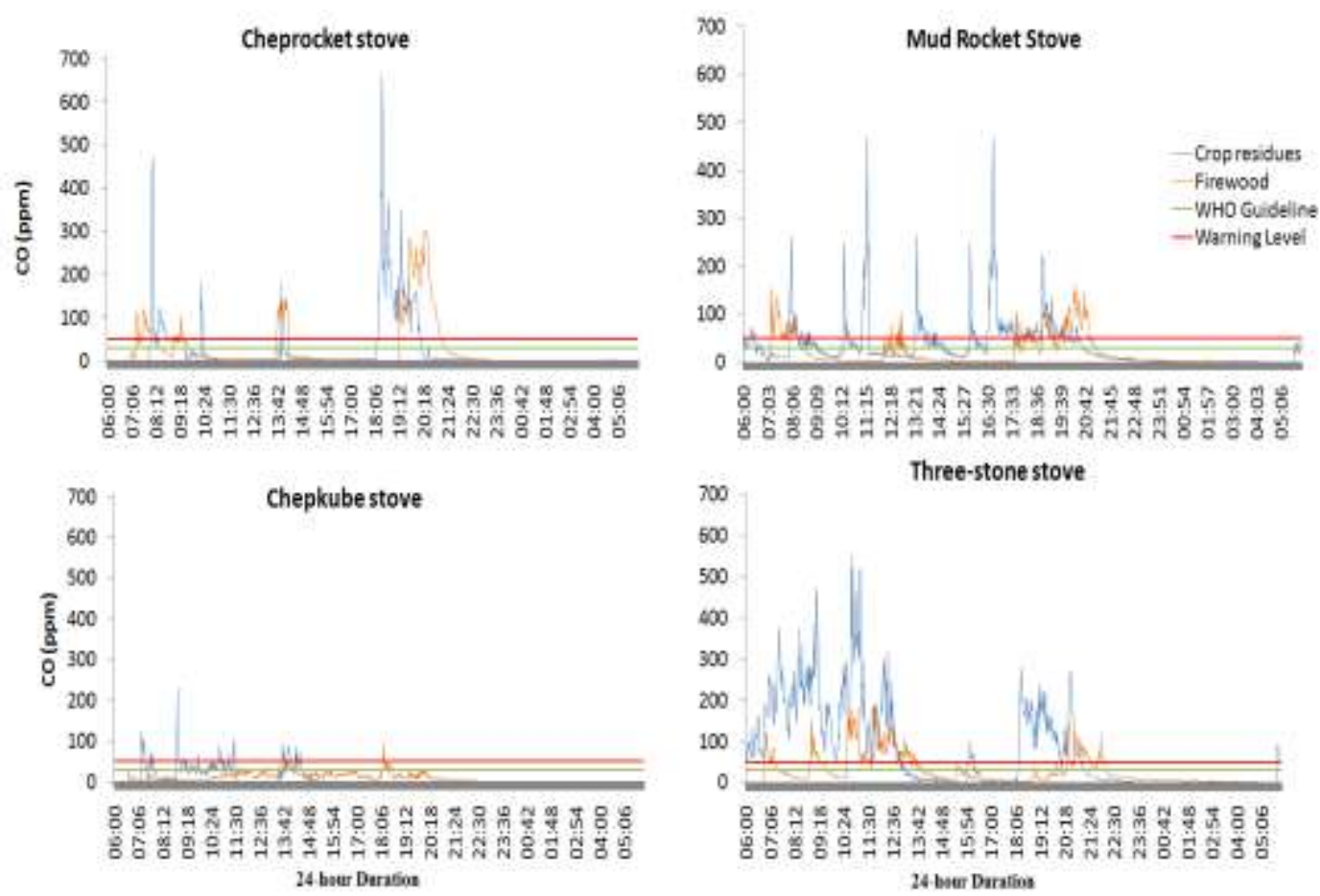

Figure 6: Diurnal Variation of CO using Different Biomass Stoves

Maximum kitchen CO concentration from Chepkube stove was $277.5 \mathrm{ppm}$ (min $-0 \mathrm{ppm}$, IQR -2.5 ppm, $p=0.000)$ and $91 \mathrm{ppm}(\mathrm{min}-0 \mathrm{ppm}, \mathrm{IQR}-14.5 \mathrm{ppm}, p=0.000)$ using crop residues and firewood fuels, respectively. As shown in Figure 6, most kitchen CO concentration using firewood were within the WHO safe limits using Chepkube stove.

At 95\% CI, peak kitchen CO concentration from three-stone stove using crop residues was $594 \mathrm{ppm}$ ( $\min -0 \mathrm{ppm}, \mathrm{IQR}-138.5 \mathrm{ppm}, p=0.000)$ and $192 \mathrm{ppm}(\mathrm{min}-0 \mathrm{ppm}$, IQR $-36 \mathrm{ppm}, p=0.000)$ using crop residues and firewood fuels, respectively. Like in all other stoves, there were several peak concentrations that exceeded both safe WHO limit and warning level as indicated in the periodical 24-hour variations in Figure 6.

\section{Discussion}

Average 24-hour $\mathrm{PM}_{2.5}$ concentrations in the kitchens using all the stoves were significantly higher than the recommended World Health Organization (WHO) threshold of $25 \mu \mathrm{g} / \mathrm{m}^{3}$. The least recorded kitchen $\mathrm{PM}_{2.5}$ concentration was from Chepkube stove; an indigenous innovation among the Kalenjin community compared to mud rocket stove and Cheprocket stoves that are considered improved biomass stoves with superior combustion technologies according to SCC-VI agroforestry (2010). Although Chepkube stove produced the least kitchen $\mathrm{PM}_{2.5}$ concentrations, the levels were 25 times higher than the recommended WHO guideline. Three-stone stove as expected had the highest kitchen $\mathrm{PM}_{2.5}$ concentrations using both firewood and crop residues as fuel with peak emissions above $52,000 \mu \mathrm{g} / \mathrm{m}^{3}$ recorded. Particulate matter concentrations in kitchens were up to 200 times higher than the 24-hour WHO safe air quality standard.

The extremely high $\mathrm{PM}_{2.5}$ concentrations recorded in the kitchens were comparable to concentrations found in other studies conducted in regions where biomass fuel use is highly prevalent (Ezzatiet al., 2000; Kilabukoet al., 2007). Smith et al. (2000) estimated household concentrations of total suspended particles in Gujarat, India, and found that indoor concentrations of TSPs in these rural huts could be as high as 10,000 $\mu \mathrm{g} / \mathrm{m}^{3}$. Results from this study corroborated with the findings of Ezzati (2000) who recorded peak kitchen PM concentrations above $55,000 \mu \mathrm{g} / \mathrm{m}^{3}$ in Central Kenya. However, $\mathrm{PM}_{2.5}$ levels reported in this study were higher than average kitchen PM concentrations of $609 \mu \mathrm{g} / \mathrm{m}^{3}$ recorded by Kalpanaet al. (2013) in India and comparatively low kitchen concentrations of $360 \mu \mathrm{g} / \mathrm{m}^{3}$ recorded in rural Peru. Bartingtonet al. (2017) recorded a mean 48-hour kitchen PM concentration of $418 \mu \mathrm{g} / \mathrm{m}^{3}$ and peak concentration of $1384 \mu \mathrm{g} / \mathrm{m}^{3}$ in Nepal. More recently, Johnson et al. (2011) performed a Monte-Carlo analysis of a single-zone box model of indoor $\mathrm{PM}_{2.5}$ concentrations from stove emissions and predicted that only about $4 \%$ of homes using wood fuel in a rocket stove; a widely known cleaner and more efficient stove, would achieve $\mathrm{WHO}$ annual $\mathrm{PM}_{2.5}$ guidelines.

The observed temporal variation in kitchen $\mathrm{PM}_{2.5}$ patterns is consistent with reported findings from comparable settings with similar kitchen and stove characteristics reported by Ezzatiet al. (2000). Overall diurnal pollutant patterns were similar in pattern but higher in magnitude than those reported from the 
SarlahiDistrict of Nepal, where average 24-hour pollutant concentrations of $\mathrm{PM}_{2.5} 650 \mu \mathrm{g} / \mathrm{m}^{3}$ was measured (Klasenet al., 2015) suggesting possible differences in local cultural cooking practices. Measured differences in $\mathrm{PM}_{2.5}$ concentrations during peak and non-peak cooking sessions were also lower than those obtained for $\mathrm{PM}_{2.5}$ average concentrations reported in low-income settings (Clark et al., 2010; Commodore et al., 2013).

The excessive kitchen $\mathrm{PM}_{2.5}$ levels recorded compared to India and Peru could be contributed by other sources in the kitchens such as kitchen construction materials such as mud which was the main material used to construct walls, earthen kitchen floors, kitchen practices such as sweeping without wetting the floor to settle the dust, increased temperatures in the poorly ventilated kitchens made in impossible for suspended particulate matters to settle down; not necessarily from biomass fuels combustion. Further there was behavioral practice of leaving kitchen windows open throughout the day. Due to draught, there was continuous motion of air in contaminated kitchens making particles difficult to settle down. Another reason was, since the study was conducted during the dry season, and people were generally preparing land in readiness for planting, outdoor particulates could have been blown through the windows in to the kitchens thus increasing kitchen PM concentrations. Poor air supply in to the combustion chamber among the rocket stove and Cheprocket stove contributed to high smoke levels during burning and simmering period compared to Chepkube stove whose air inlet is enlarged thus improving combustion.

One of the greatest factors leading to the high pollutant concentrations and exposures is the high usage of solid biomass fuels at $97 \%$ wood and $80 \%$ crop residue in all households monitored for IAP. Although there was a perennial misconception that mud rocket stove can save more fuel compared to Chepkube stove, this study however proved that Chepkube stove saved more on fuel which would have contributed to the observed reduced emissions. Fuel consumption using Chepkube stove was $0.33 \mathrm{~kg} / \mathrm{person} / \mathrm{day}$ and $0.32 \mathrm{~kg} / \mathrm{person} / \mathrm{day}$ lower compared to mud rocket stove and Cheprocket stove, respectively. As expected, three stone stove had the highest fuel consumption at $1.98 \mathrm{~kg} /$ person/day. Higher fuel consumption from mud rocket stove and Cheprocket stove could have contributed to the increased kitchen PM emissions compared to Chepkube stove. This finding is supported by Suzanne et al. (2014) who found that population living in rural homes Peru and cooking primarily with solid biomass fuels experienced daily indoor PM concentrations that were 6-fold higher than participants living in the urban households or using lesser solid biomass fuels.

Higher pollutant concentrations were also observed during cooking sessions compared to when the stoves were idle suggesting that the more the cooking; the more the pollutant concentrations in the kitchens. This finding is supported by Yamamoto et al. (2014) who recorded higher mean 24-hour PM $_{10}$ concentrations during cooking sessions compared to non-cooking sessions in Burkina Faso. Similarly, a study by Kilabukoet al. (2007) in rural Tanzania recorded significantly higher $\mathrm{PM}_{2.5}$ concentrations during cooking periods compared to simmering periods. The effects of the extensive use of biomass fuel found in the study area could overwhelm any benefits that might be observed in terms of lower concentrations from improved biomass stoves. In this case, the introduction of fuel subsidies to encourage movement up the energy ladder to liquid petroleum fuels and gas stoves may have a greater impact on reducing overall air pollution exposures and risks to health.

The high levels of kitchen $\mathrm{PM}_{2.5}$ concentrations in rural kitchens using biomass fuels imply that indoor air pollution is still a real threat to the public health in the country. Respiratory infections due to indoor air pollution are likely to be rampant especially in rural areas. It was also observed that what is referred to as improved biomass stove such as mud rocket stoves and Cheprocket stoves were associated with higher kitchen PM emissions compared to Chepkube stove suggesting that although these stoves are referred to as improved, they must drastically improve to meet WHO air quality guidelines through measures such as fitting with chimneys to drive the smoke out of the cooking area.

On average Carbon Monoxide (CO) recorded from different biomass stoves was higher than World Health Organization threshold of $6 \mathrm{ppm}$ in a 24-hour period. Crop residue fuel resulted in higher $\mathrm{CO}$ emissions compared to firewood probably because of the fuel properties. Cheprocket and MRS did not have significantly differently $\mathrm{CO}$ emissions because they use same combustion principle; the rocket principle. However, the Chepkube had lower $\mathrm{CO}$ emissions because of improved air circulation in the combustion chamber.

The highest average 24-hour CO kitchen concentration was from three-stone stove at $75 \mathrm{ppm}$ using crop residues as fuel. The highest 1 -hour peak of carbon monoxide kitchen concentration was recorded from Cheprocket stove and mud rocket stove probably due to the poor air circulation in to the combustion chamber. Households using crop residue fuel sources had the highest peak concentrations and greatest variability of CO. The highest recorded peak 1-hour $\mathrm{CO}$ concentration $(658 \mathrm{ppm})$ from Cheprocket stove exceeded the WHO AQG 60-min exposure guideline of $30 \mathrm{ppm}$ (WHO, 2010). Peak CO concentrations can be explained by periods such as fire lighting and any disturbance in the fire for example adding more wood fuel during cooking or pushing fuel in to the combustion chamber. A relatively lower CO emission from Chepkube stove compared to other stoves was probably as a result of lower fuel consumption. The observed temporal variation in 24-hour CO patterns is consistent with findings from comparable settings with similar kitchen and stove characteristics to those reported from central Kenya by Ezzatiet al. (2000). Overall diurnal CO patterns were similar in pattern but 
lower in magnitude to those reported from the Sarlahi District of Nepal, where average 24-hour concentrations of CO $9.1 \mathrm{ppm}$ were recorded (Klasenet al., 2015) suggesting possible differences in local cultural cooking practices such as number of meals cooked and kitchen designs.

\subsection{Conclusion}

\section{Conclusionand Recommendations}

Household indoor PM and kitchen concentrations associated with biomass fuel combustion in the study area exceed WHO indoor safe limits and are in the hazardous range for human health. The extremely high kitchen $\mathrm{PM}_{2.5}$ concentrations suggest that MRS and Cheprocket stoves cannot be an intervention for health effects of $\mathrm{PM}_{2.5}$ which are of most interest in HAP.

Traditional innovations should not always be branded primitive before due testing and acquiring adequate proof of their performance level. Chepkube stove; a local innovation among the Kalenjin community is an improved biomass technology capable of saving more fuel and emitting lesser PM and CO emissions from biomass combustion compared to mud rocket stove and Cheprocket stoves; long perceived improved biomass stoves.

\subsection{Recommendations}

1. The study recommends for initiatives that focus on holistic approach to kitchen PM concentrations reduction where it adopts a systems approach to improving behavioral and cooking practices and kitchen characteristics especially construction materials and designs.

2. An epidemiological study to be carried out to assess the linkage between PM exposures and respiratory infections in the region

References

[1] Akunne, A. F., Louis, V. R., Sanon, M., \& Sauerborn, R. (2006). Biomass solid fuel and acute respiratory infections: the ventilation factor. International Journal of Hygiene Environmental Health, 209, 445 - 450.

[2] Bartington S.E, Bakolis I., Devakumar D., Kurmi O. P., Gulliver J., Chaube G., Manandhar D. S., Saville N. M., Costello A., Osrin D., Hansell A. L., \& Ayres J. G. (2017). Patterns of domestic exposure to carbon monoxide and particulate matter in households using biomass fuel in Janakpur, Nepal. Environmental Pollution, 220, 38 - 45.

[3] Bruce, N., McCracken, J., Albalak, R., Schei, M. A., Smith, K. R., Lopez, V., \& West, C. (2004).Impact of improved stoves, house construction and child location on levels of indoor air pollution exposure in young Guatemalan children. Journal of Exposure Analysis and Environmental Epidemiology, 14, 26-33.

[4] Bruce, N., Fullerton, D.G., \& Gordon, S.B. (2008). Indoor air pollution from biomass fuel smoke is a major health concern in the developing world. Transactions of the Royal Society of Tropical Medicine and Hygiene Royal Society of Tropical Medicine and Hygiene, 102, $843-851$.

[5] Burnett, R.T., Pope, C. A., Ezzati, M., Olives, C., Lim, S. S., \& Mehta, S. (2014). An Integrated risk function for estimating the global burden of disease attributable to ambient fine particulate matter exposure. Environmental health perspectives, $122,397-403$.

[6] Clark, M. L., Reynolds, S. J., Burch, J. B., Conway, S., Bachand, A. M., \& Peel, J. L. (2010). Indoor air pollution, cookstove quality, and housing characteristics in two Honduran communities. Environmental Research, 110, 12 - 18.

[7] Commodore, A. A., Hartinger, S. M., Lanata, C. F., M€ausezahl, D., Gil, A. I., Hall, D. B., Aguilar-Villalobos, M., \&Naeher, L. P. (2013). A pilot study characterizing real time exposures to particulate matter and carbon monoxide from cookstove related woodsmoke in rural Peru. Atmospheric Environment, 79, 380 - 384.

[8] Ellegard A. (1996). "Cooking Fuel Smoke and Respiratory Symptoms among Women inLow-Income Areas in Maputo," Environmental Health Perspectives, 104, 980 - 985.

[9] Ezzati, M. (2000). Energy technology, indoor air pollution, and respiratory infections in developing countries a field study from central Kenya. A dissertation presented to the faculty of Princeton University in candidacy for the degree of doctor of philosophy recommended for acceptance by the Woodrow Wilson School of public and international affairs. November 2000

[10] Ezzati, M., Saleh, H., \& Kammen, D. M. (2000). The Contributions of Emissions and Spatial Microenvironments to Exposure to Indoor Air Pollution from Biomass Combustion in Kenya. Environmental Health Perspective, 108, 833 - 839.

[11] Ezzati, M., \&Kammen, D. M. (2001). Quantifying the effects of exposure to indoor air pollution from biomass combustion on acute respiratory infections in developing countries. Environmental Health Perspective, 109, 481 - 489.

[12] Ezzati, M., \&Kammen, D. M. (2002). The health impacts of exposure to indoor air pollution from solid fuels in developing countries: knowledge, gaps, and data needs. Environmental Health Perspectives, 110, 1057 - 1068.

[13] Government of Kenya, (GoK). (2002). Study on Kenya's Energy Demand, Supply and Policy Strategy for Households, Small Scale Industries and Service Establishments. Ministry of Energy (MoE), Nairobi.

[14] Government of Kenya, (GoK). (2013a). Trans Nzoia County Integrated Development Plan 2013 - 2017. Trans Nzoia County government, 2013.

[15] Government of Kenya, (GoK). (2013b). Bungoma County Integrated Development Plan 2013 - 2017. Bungoma County government, 2013.

[16] Johnson, M., Edwards, R., Berrueta, V., \&Masera, O., (2011). New approaches to performance testing of improved cookstoves. Environment Science \& Technology, 44, $368-74$.

[17] Kalpana, B., Santu, G., Bhaswati, G., Sankar, S., Nigel, B., Douglas, F. B., \& Kirk, R. S. (2013). State and national household concentrations of $\mathrm{PM}_{2.5}$ from solid cookfuel use: Results from measurements and modeling in India for estimation of the global burden of disease. Journal of Environmental health, 12, $77-90$.

[18] Kilabuko, J. H., Matsuki, H., \& Nakai, S. (2007). Air quality and acute respiratory illness in biomass fuel using homes in Bagamoyo, Tanzania. International Journal of Environmental Research and Public Health,4, 39 - 44.

[19] Klasen, E. M., Wills, B., Naithani, N., Gilman, R.H., Tielsch, J. M., Chiang, M., Khatry, S., Breysse, P. N., Menya, D. M., Apaka, C., Carter, J. E., Sherman, C. B., Miranda, J., \&Checkley, W. (2015). Low correlation between household carbon monoxide and 
particulate matter concentrations from biomass-related pollution in three resource-poor settings. Environmental Research, 142,424 $-431$.

[20] Lim, S. S., Vos, T., Flaxman, A. D., Danaei, G., Shibuya, K., \& Adair-Rohani, H. (2012). A comparative risk assessment of burden of disease and injury attributable to 67 risk factors and risk factor clusters in 21 regions, 1990 - 2010: a systematic analysis for the Global Burden of Disease Study 2010. Lancet, 380, 2224 - 2260.

[21] Moi University, (2017). Trans Nzoia and Bungoma county Maps. Department of Geography, Moi university press, 2017.

[22] Moradi, A. (2006). The nutritional status of women in sub-Saharan Africa, 1950-1980, reducing poverty and inequality: how can Africa be included? Centre for the Study of African Economies Conference. University of Oxford, Oxford.

[23] Naeher, L. P., Brauer, M., Lipsett, M., Zelikoff, J. T., Simpson, C. D., Koenig, J. Q., \& Smith, K. R. (2007). Woodsmoke health effects: a review. Inhalation toxicology, 19, $67-106$.

[24] Ramanathan, V., \& Carmichael, G. (2008). Global and regional climate changes due to black carbon. NatureGeoscience, 1, 221 227.

[25] SCC-VI Agro-forestry. (2010). Energy in Emergency settings. A practitioner's journal on household energy, stoves and poverty reduction. Household energy Network.

[26] Smith, K. R., Samet, J. M., Romieu, I., \& Bruce, N. (2000). Indoor air pollution in developing countries and acute lower respiratory infections in children. Thorax,55, $518-532$.

[27] Smith, K. R., Dutta, K., Chengappa, C., Gusain, P. P. S., Berrueta, O. M., Victor, Edwards, R., Bailis, R. \& Shields, K. N. (2007). Monitoring and evaluation of improved biomass cookstove programs for indoor air quality and stove performance: conclusions from the Household Energy and Health Project, Energy for Sustainable Development, 11, 5-18.

[28] Suzanne, L., Pollard, D. A., Williams. L., Patrick, N. B., Patrick, A. B., Laura, M. G., Robert, H. G., Jaime, J. M., \& William, C. (2014). A cross-sectional study of determinants of indoor environmental exposures in households with and without chronic exposure to biomass fuel smoke. Environmental Health, 13, $21-32$.

[29] UNEP, UNDP, World Bank, World Resources Institute. (1998). World resources: a guide to the global environment. Oxford, Oxford University Press, 1998.

[30] University of California, (2003). Laboratory Standard Operating Procedure: personal Data Ram Model pDR-1000AN. School of Population and Public Health, Vancouver, Berkeley.

[31] University of California, (2016). Catalogue of methods for evaluating household energy interventions. Center for Entrepreneurship in International Health and Development, Berkeley, 2016, California.

[32] World Health Organization (WHO). (2007). The Global Burden of Disease: 2004 Update. Geneva: World Health Organization, 2008.

[33] World Health Organization, (WHO). (2010). Guidelines for Indoor Air Quality: Selected Pollutants. The WHO European Centre for Environment and Health, Bonn, 2010.

[34] World Health Organization (WHO). (2014). Indoor Air Quality Guidelines: Household Fuel Combustion: World Health Organization, Geneva, 2014.

[35] Yamamoto, S. S., Louis, V. R., Sié, A., \& Sauerborn, R. (2014). Biomass smoke in Burkina Faso: what is the relationship between particulate matter, carbon monoxide, and kitchen characteristics? Environmental Science and Pollution Research, $21,2581-2591$.

\footnotetext{
Carol Munini Munyao. "Household Air Pollutionin Rural Western Kenya: A Major Public Health Challenge." IOSR Journal of Environmental Science, Toxicology and Food Technology (IOSR-JESTFT) 11.7 (217): 87-96.
} 